\title{
Selective Photocatalytic Oxidation of 5-Hydroxymethylfurfural to 2,5- Furandicarboxaldehyde by Polymeric Carbon Nitride-Hydrogen Peroxide Adduct
}

\author{
M. Ilkaeva, ${ }^{\mathrm{a}}$ I. Krivtsov, ${ }^{\text {a,b }}$ E.I. García-López, ${ }^{\mathrm{c}}$ G. Marcì, ${ }^{\mathrm{c}}$ O. Khainakova, ${ }^{\mathrm{a}}$ J.R. García, ${ }^{\mathrm{a}}$ L. Palmisano, ${ }^{\mathrm{c}}$ E. \\ Díaz, ${ }^{\mathrm{d}}$ S. Ordóñez ${ }^{\mathrm{d}}$ \\ ${ }^{a}$ Departments of Organic and Inorganic Chemistry, Physical and Analytical Chemistry, University of Oviedo-CINN, 33006 Oviedo, \\ Spain. \\ ${ }^{\mathrm{b}}$ Nanotechnology Education and Research Center, South Ural State University, 454080 Chelyabinsk, Russia. \\ c "Schiavello-Grillone" Photocatalysis Group. Dipartimento di Energia, Ingegneria dell'informazione e modelli Matematici (DEIM), \\ Università di Palermo, Viale delle Scienze, 90128 Palermo, Italy. \\ ${ }^{\mathrm{d}}$ Department of Chemical and Environmental Engineering, University of Oviedo, 33006 Oviedo, Spain. \\ Corresponding author e-mail: krivtsovigor@uniovi.es; Tel: +34 985103030
}

\begin{abstract}
Polymeric carbon nitride-hydrogen peroxide adduct $\left(\mathrm{PCN}-\mathrm{H}_{2} \mathrm{O}_{2}\right)$ has been prepared, thoroughly characterised and its application for selective photocatalytic conversion of 5-hydroxymethylfurfural (HMF) to 2,5-furandicarboxaldehyde (FDC) in aqueous suspension has been studied. The $\mathrm{PCN}-\mathrm{H}_{2} \mathrm{O}_{2}$ adduct is stable in aqueous suspension under UV and solar irradiation up to $100{ }^{\circ} \mathrm{C}$. It is also stable up to $200{ }^{\circ} \mathrm{C}$ if heated in air, while at temperatures close to $300{ }^{\circ} \mathrm{C}$ its decomposition takes place. Based on the obtained characterisation data it has been proposed that $\mathrm{H}_{2} \mathrm{O}_{2}$ attaches to the non-polymerised carbon nitride species and to the heptazine nitrogen atoms, thus producing strong hydrogen bonding within the PCN- $\mathrm{H}_{2} \mathrm{O}_{2}$ adduct. The blockage of the surface amino-groups in $\mathrm{PCN}-\mathrm{H}_{2} \mathrm{O}_{2}$ by $\mathrm{H}_{2} \mathrm{O}_{2}$ hinders the interaction of HMF with these sites, which are responsible for unselective substrate conversion. PCN$\mathrm{H}_{2} \mathrm{O}_{2}$ possesses a superior selectivity in natural solar light assisted oxidation of HMF to FDC reaching $80 \%$ with respect to its thermally etched PCN counterpart, which gives rise to a $40-50 \%$ selectivity. We believe that the exceptional performance of the applied photocatalyst in the selective photocatalytic conversion of HMF to a high added value FDC in a green solvent under natural illumination makes a significant contribution to the development of environmentally friendly technologies for biomass valorisation.
\end{abstract}

Keywords: photocatalysis; carbon nitride; selective photo-oxidation; 5-hydroxymethylfurfural; 2,5furandicarboxaldehyde. 


\section{Introduction}

Wood industry and agricultural sector release a large amount of by-products and wastes, which if processed appropriately, can be converted into a range of valuable chemicals or fuels. This renewable feedstock known under the general term "biomass", despite being used for multiple purposes, is still in the spotlight of the research community, inasmuch as newly emerged technologies allow benefiting from its more complete use. Cellulose, an abundant biomass compound, can be upgraded by undergoing hydrolysis producing hexose sugars, which after being subsequently dehydrated give a biomass platform molecule 5-hydroxymethyl furfural (HMF) [1,2]. While HMF itself has few applications, the products of its oxidation 2,5furandicarboxylic acid (FDCA) and 2,5-diformylfuran, also known as 2,5-furandicarboxaldehyde (FDC), possess properties making them valuable for biopolymer production [3-7]. Many catalytic procedures have been developed for obtaining both FDCA [8,9] and FDC [9-14] by oxidising HMF, but photocatalysis is among the most economic and greener alternatives as it benefits from a nearly free energy source, which is solar radiation, and does not require toxic oxidants. The outburst of interest toward semiconductor-assisted selective photo-oxidation has already resulted in an impressive number of exhaustive reviews on mechanisms and applied aspects of this process [15-20]. Light-initiated transformation of biomass aiming to produce fuel has recently been reported by Wakerley et al. [21], while the approaches for its chemical upgrading has been reviewed in [22-23].

HMF itself was subjected to electrophotocatalytic [24] and photocatalytic conversion in aqueous phase using $\mathrm{TiO}_{2}$ as the photocatalyst, and FDC was found to be the main oxidation product of this reaction [25,26]. Although $\mathrm{TiO}_{2}$, and especially $\mathrm{N}$-doped $\mathrm{TiO}_{2}$ promoted the formation of FDC from HMF, the selectivity of this process was low reaching $30 \%$ for the best photocatalysts, owing to formation on the $\mathrm{TiO}_{2}$ surface of highly oxidative hydroxyl radicals inducing the substrate mineralisation [26]. Obviously, an alternative material for such transformation was in demand. It has not been long since polymeric carbon nitride (PCN) (the recommended term for graphitic carbon nitride, $\mathrm{g}-\mathrm{C}_{3} \mathrm{~N}_{4}$ ) [27] photocatalyst has emerged [28]. In addition to its high ability to reduce water protons to molecular hydrogen, it possesses a valence band (VB) potential which does not permit direct water oxidation to ${ }^{\circ} \mathrm{OH}$ radicals [28], hence reducing the presence of notoriously unselective oxidative species in a water suspension of photocatalysts with organic 
compounds. Despite this attractive property, this material has mostly been used for conversion of aromatic alcohols [29-32] and hydrocarbons [33-36] in organic solvents, while reports on its performance in aqueous phase are scarce [37-38]. Recently, the enhanced selectivity of PCN for aqueous phase HMF to FDC photo-oxidation with respect to that previously achieved in the presence of $\mathrm{TiO}_{2}$ [25] has been reported [39-40]. A detrimental effect of the presence of nonpolymerised carbon nitride species on the selectivity of photo-oxidation has also been observed [39]. Thermal etching applied to bulk PCN, principally with the purpose of increasing its specific surface area (SSA), also eliminated excessive $\mathrm{NH}$ and $\mathrm{NH}_{2}$ moieties from the PCN surface resulting in the growth of selectivity toward the FDC production from $30 \%$ to $50 \%$ under solar irradiation [39]. The importance of controlling the interaction of substrate with the surface functional groups of $\mathrm{PCN}$ was even more stressed for chemoselective $\mathrm{C}-\mathrm{H}$ bond oxidation of alkylphenolethoxylate molecules [41]. In this paper, we report the application of the $\mathrm{PCN}-\mathrm{H}_{2} \mathrm{O}_{2}$ adduct for highly selective photocatalytic oxidation of HMF to FDC in aqueous medium under both UV and natural solar light irradiation.

\section{Experimental Section}

\section{Materials}

Melamine (99\%), $30 \mathrm{wt} \%$ hydrogen peroxide water solution, 5-hydroxymethylfurfural (HMF) ( $\geq 99 \%$ ), 2,5-furandicarboxyaldehyde (FDC) ( $\geq 99 \%$ ), and 5-formyl-2-furoic acid (FFA) ( $\geq 99 \%$ ) were purchased from Aldrich.

\section{Synthesis}

The bulk PCN was prepared via the thermal condensation method using melamine as the precursor according to the procedure described by Wang et al. [42]. Briefly, $10 \mathrm{~g}$ of melamine was placed in a covered ceramic crucible and heated in a muffle furnace at $2{ }^{\circ} \mathrm{C} \min ^{-1}$ up to 520 ${ }^{\circ} \mathrm{C}$. Once the temperature was reached it was left for $2 \mathrm{~h}$ and slowly cooled down afterwards. By this procedure, $6 \mathrm{~g}$ of $\mathrm{PCN}$ was obtained. Bulk PCN was then subjected to thermal etching as previously reported $[39,43]$, in order to produce high SSA PCN. For this purpose, $6 \mathrm{~g}$ of the bulk carbon nitride was powdered in a mortar, evenly spread on the bottom of a ceramic bowl with a diameter of $12 \mathrm{~cm}$, heated in a static air atmosphere at $500{ }^{\circ} \mathrm{C}$ by using a temperature ramp of 3 
${ }^{\circ} \mathrm{C} \min ^{-1}$ and maintained for $4 \mathrm{~h}$ at the reached temperature before being cooled down. This procedure yielded $2.8 \mathrm{~g}$ of the thermally etched PCN sample, designated as TE. Finally, the PCN$\mathrm{H}_{2} \mathrm{O}_{2}$ adduct, whose preparation and characterisation were reported elsewhere [41], was synthesized. For this, $2.8 \mathrm{~g}$ of TE was stirred in $50 \mathrm{~mL}$ of $\mathrm{H}_{2} \mathrm{O}_{2}$ aqueous solution (30 wt $\%$ ) in an open beaker while heating at $70{ }^{\circ} \mathrm{C}$ until complete evaporation of the liquid was achieved. The obtained solid was washed thoroughly with deionized water, until $\mathrm{H}_{2} \mathrm{O}_{2}$ was no longer detected in the washing liquid, filtered and finally dried at $80{ }^{\circ} \mathrm{C}$ for $24 \mathrm{~h}$ giving the $\mathrm{PCN}-\mathrm{H}_{2} \mathrm{O}_{2}$ adduct (TEO). After that, aliquots of the TEO sample, $0.87 \mathrm{~g}$ in each case, were treated at 200, 300, and $400{ }^{\circ} \mathrm{C}$ in air for $2 \mathrm{~h}$, and the resulting samples were coded as TEOx, where " $x$ " indicated the treatment temperature. For the sake of comparison, two more samples were synthesized. Thermally etched TEO450 was prepared by treating the TEO sample at $450{ }^{\circ} \mathrm{C}$ in air. $\mathrm{H}_{2} \mathrm{O}_{2}$ modification of TE was also carried out using reflux treatment at $70{ }^{\circ} \mathrm{C}$ (TEO_R). Melaminehydrogen peroxide adduct (MHP) was prepared and used as the reference for the assignment of carbon nitride surface species formed after the reaction with hydrogen peroxide. For this purpose, $10 \mathrm{~g}$ of melamine was mixed with $50 \mathrm{~mL}$ of $30 \mathrm{wt} \% \mathrm{H}_{2} \mathrm{O}_{2}$ and let stirring while heated at $70{ }^{\circ} \mathrm{C}$ until the solvent was evaporated. The obtained solid was dried at $70{ }^{\circ} \mathrm{C}$ for $24 \mathrm{~h}$.

\section{Characterisation}

Powder XRD patterns were registered in an X'pert PANanalytical diffractometer, using a Nifiltered $\mathrm{Cu}-\mathrm{K} \alpha$ radiation source and PixCel1D $(\mathrm{tm})$ detector. Infrared spectra of the samples were recorded with $4 \mathrm{~cm}^{-1}$ resolution using an ATR module of a Varian 620-IR spectrometer. The surface elemental composition of the $\mathrm{PCN}$ and $\mathrm{PCN}-\mathrm{H}_{2} \mathrm{O}_{2}$ samples, their valence band (VB) potentials, and the binding energies of $\mathrm{C}, \mathrm{N}$ and $\mathrm{O}$ were measured by $\mathrm{X}$-ray photoelectron spectroscopy (XPS) on a SPECS system equipped with a Hemispherical Phoibos analyser operating in a constant pass energy, using $\mathrm{MgKa}$ radiation $(\mathrm{h} \cdot \mathrm{v}=1253.6 \mathrm{eV})$. The absence of $\mathrm{C}-$ $\mathrm{C}$ bonds in carbon nitride made possible taking a signal of adventitious carbon at $284.8 \mathrm{eV}$ as a reference. The elemental composition was estimated from the deconvoluted high-resolution data as to remove the contribution of adventitious carbon. The value of conduction band potential of the PCN samples was estimated by subtracting the value of band gap energy (BG) from that of the valence band energy (VB). The solid-state ${ }^{13} \mathrm{C},{ }^{1} \mathrm{H}$ MAS NMR, and ${ }^{1} \mathrm{H}-{ }^{13} \mathrm{C}$ CPMAS NMR spectra 
were registered at the spinning rates of $5 \mathrm{kHz}$ for ${ }^{13} \mathrm{C}$, and $8 \mathrm{kHz}$ for the other measurements using a Bruker Avance III 400WB spectrometer. A Shimadzu UV-2401 PC spectrophotometer equipped with an integrated sphere was used to obtain diffusive reflectance spectra (DRS) from the prepared samples supported on $\mathrm{BaSO}_{4}$ pellets. The $\mathrm{BG}$ was estimated by applying the Kubelka-Munk function to the DRS data considering PCN as an indirect semiconductor. Photoluminescence spectra were recorded for the obtained materials by means of a standard spectrofluorimeter Edinburgh Instruments FLSP920 equipped with a $450 \mathrm{~W}$ Xe lamp as an excitation source (365 and $455 \mathrm{~nm}$ wavelengths were selected for the samples excitation). A Micromeritics ASAP 2020 was used to obtain adsorption-desorption isotherms of $\mathrm{N}_{2}$ at $77 \mathrm{~K}$. Specific surface area (SSA) was calculated from the nitrogen adsorption data by BET equation. Before the experiment, the samples were outgassed under vacuum at $200{ }^{\circ} \mathrm{C}$. The temperature programmed desorption mass-spectroscopic (TPD-MS) analysis was carried out with help of a Micromeritics Autochem II 2920 system coupled with a ThermoStar mass spectrometer. For the analysis, $100 \mathrm{mg}$ of a powdered PCN was put onto a fibreglass support inside a quartz U-tube, purged for $60 \mathrm{~min}$ with argon gas flowing through the sample at the rate of $10 \mathrm{~mL} \mathrm{~min}^{-1}$ at $35^{\circ} \mathrm{C}$ and then heated at $10{ }^{\circ} \mathrm{C} \min ^{-1}$ up to $400{ }^{\circ} \mathrm{C}$. The concentration of $\mathrm{H}_{2} \mathrm{O}_{2}$ released into water suspension by the $\mathrm{PCN}-\mathrm{H}_{2} \mathrm{O}_{2}$ adduct was estimated photocolourimetrically by using titanium oxysulfate based method.

\section{Photocatalytic oxidation of HMF}

Partial photocatalytic oxidation of HMF to FDC under UV-light was carried out by using the experimental set-up described elsewhere [39]. A water-cooled Pyrex reactor containing $150 \mathrm{~mL}$ of aqueous suspension was irradiated with six Actinic BL TL MINI 15 W/10 Philips fluorescent lamps having an irradiation maximum at $365 \mathrm{~nm}$. The initial HMF concentration was $0.5 \mathrm{mM}$ at the natural $\mathrm{pH}$ if not stated otherwise. The amount of solid photocatalyst used for the experiments was $100 \mathrm{mg}$. In this way, all the entering photons were virtually absorbed by the suspension. The impinging radiation energy in the range $315-400 \mathrm{~nm}$ was measured by a radiometer Delta $\mathrm{Ohm}$ DO9721 with a UVA probe and its average value was $3.9 \mathrm{~W} \mathrm{~m}^{-2}$. The performance of the most efficient photocatalyst (TEO) was tested in a series of three consecutive reaction runs. The suspension of TEO was left for $24 \mathrm{~h}$ to separate the photocatalyst after the photocatalytic 
reaction. Then, the limpid solution was removed, $150 \mathrm{~mL}$ of fresh HMF $0.5 \mathrm{mM}$ solution was introduced into the reactor and the test was repeated. Samples of the irradiated solution were withdrawn at fixed time intervals and immediately filtered through $0.25 \mu \mathrm{m}$ membranes (polypropylene, VWR) to separate the photocatalyst particles. Liquid aliquots were analysed by a Thermo Scientific Dionex UltiMate 3000 HPLC equipped with a Diode Array detector and a REZEK ROA organic acid $\mathrm{H}^{+}$column with aqueous $2.5 \mathrm{mM} \mathrm{H}_{2} \mathrm{SO}_{4}$ solution mobile phase at a flow rate of $0.6 \mathrm{~mL} \mathrm{~min}^{-1}$. The concentrations of HMF, FDC and FFA were determined. Standards purchased from Sigma-Aldrich with a purity $>99 \%$ were used to identify the products formed during the reaction and to obtain the calibration curves.

The photocatalytic reactions under natural solar irradiation were carried out on clear sunny days from March to May in Palermo (Italy) from 9:30 to 13:30. Typically, $75 \mathrm{~mL}$ of $0.5 \mathrm{mM}$ HMF solution and $50 \mathrm{mg}$ of the $\mathrm{PCN}$ or $\mathrm{PCN}-\mathrm{H}_{2} \mathrm{O}_{2}$ samples were introduced into a round-shaped Pyrex batch reactor having a total volume of $125 \mathrm{~mL}$ and a diameter of $10 \mathrm{~cm}$. Additionally, the TEO sample was tested under the same conditions, but at initial HMF concentrations of $1 \mathrm{mM}$ and 2 $\mathrm{mM}$. The suspensions of the PCN samples in HMF solution were continuously magnetically stirred and probes of approximately $2.5 \mathrm{~mL}$ were withdrawn every $30 \mathrm{~min}$ and analysed by using the previously described analytical procedure. The photon flux in the range of 315-400 nm, which largely determines the reactivity of PCN under present conditions [39], was measured every 10 min throughout the photocatalytic runs, and the cumulative energy (E) was estimated based on the obtained data. The E value allows the comparison of photoreactivity results obtained under natural sunlight irradiation at different meteorological conditions. It is given by:

$E=\int_{0}^{t} I(t) d t$

in which "I(t)" is the instantaneous photon flow and " $t$ " the irradiation time. The values of "I $(t)$ " were calculated from the recorded values of irradiance, UVG(t), by using the following relationship:

$I(t)=U V G(t) \cdot S$

in which "S" is the total irradiated surface and "UVG" is the irradiance (in the $315-400 \mathrm{~nm}$ wavelength range) [44].

The detection of hydroxyl radicals was carried out by a standard terephthalic acid (TA) method [45]. For this, $12 \mathrm{mg}$ of $\mathrm{PCN}$ was suspended in $150 \mathrm{~mL}$ of $3 \mathrm{M}$ solution of TA in $0.01 \mathrm{M}$ of 
$\mathrm{NaOH}$. The suspension was irradiated in the same set-up described above, the samples were withdrawn at fixed time intervals and PL spectra of the formed hydroxyterephthalic acid were recorded at excitation wavelength of $310 \mathrm{~nm}$.

\section{Results and Discussion}

\section{XRD and FTIR}

According to the XRD patterns of the thermally etched PCN and the PCN- $\mathrm{H}_{2} \mathrm{O}_{2}$ adduct samples shown in Figure 1, the typical for PCN reflections of (002), (100), and (101) planes are observed. Noteworthy, the full-width at half-maximum (FWHM) of the diffraction peak at $27.7^{\circ}(2 \theta)$ is decreased to $1.46^{\circ}$ for the TEO sample with respect to that of $\mathbf{T E}\left(1.66^{\circ}\right)$, indicating the change in preferential orientation or bonding in the adduct, also noted elsewhere [41] (Fig. 1 inset). This finding differs from other works reporting the use of $\mathrm{H}_{2} \mathrm{O}_{2}$ for hydrothermal carbon nitride treatment, where harsh conditions favoured exfoliation of $\mathrm{PCN}$, consequently reducing the intensity of diffraction maxima [46,47]. Thermal treatment at 200 and $400{ }^{\circ} \mathrm{C}$ applied to the TEO sample does not lead to further changes of FWHM of the (002) peak, which is maintained in the

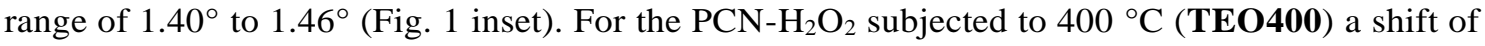
the peak position is clearly seen on the XRD pattern of this sample (Fig. 1 inset), implying that thermal etching has already taken place at $400{ }^{\circ} \mathrm{C}[48]$.

\section{FIGURE 1}

FTIR study is in agreement with the discussed XRD results, as it confirms that no major changes in polymeric $\mathrm{C}_{3} \mathrm{~N}_{4}$ structure occur neither after the reaction with $\mathrm{H}_{2} \mathrm{O}_{2}$ nor after the subsequent heating (see Electronic Supplementary Information, Fig. S1). The range of wavenumbers from 1100 to $1700 \mathrm{~cm}^{-1}$ is typical of $\mathrm{C}-\mathrm{N}$ stretching vibrations in heptazine heterocycles (Fig. S1), and it remains almost identical whatever treatment is applied to the TE or TEO samples.

\section{XPS study}

The C 1s XPS spectra (Fig. S2) show that the positions of the corresponding maxima do not change and the profiles of the spectra are not significantly modified after the applied treatment. The XPS probing of the $\mathrm{N} 1 \mathrm{~s}$ region results in a broad maximum, which can be deconvoluted into the three major contributions from $\mathrm{C}-\mathrm{N}=\mathrm{C}(\mathrm{N} 1), \mathrm{N}-(\mathrm{C})_{3}(\mathrm{~N} 2)$ and $\mathrm{C}-\mathrm{N}-\mathrm{H}(\mathrm{N} 3)$ species (Fig. S3). 
The ratio of N1 to N3 remains nearly constant for all the samples, whereas it is not the case of the N1/N2 ratio (Table S1). Due to the significant peak width and the possible superposition of the signals from several $\mathrm{N}$-containing moieties, it is difficult to unambiguously attribute the observed changes to certain groups in $\mathrm{PCN}-\mathrm{H}_{2} \mathrm{O}_{2}$. However, one can suggest that the decrease of the $\mathrm{N} 1$ to N2 ratio for TEO is a consequence of the enhanced condensation degree of PCN, while the following changes manifested by the samples subjected to thermal treatment at 200 and $300{ }^{\circ} \mathrm{C}$ result most likely from the reaction of evolving hydrogen peroxide with carbon nitride (Table $\mathrm{S} 1$ ). In accordance with the previously reported data [41], XPS results show the increased surface oxygen content in TEO contrary to its unmodified counterpart, the TE sample (Table 1). Interestingly, the concentration of surface oxygen decreases slightly after the material is heated at $200{ }^{\circ} \mathrm{C}$, but it drops down, even below the value obtained for TE, in the samples heated up to 300 and $400^{\circ} \mathrm{C}$ (Table 1$)$.

\section{TABLE 1}

\section{FIGURE 2}

The nature of the oxygen-containing species in the $\mathrm{PCN}-\mathrm{H}_{2} \mathrm{O}_{2}$ samples is determined from the $\mathrm{O}$ 1s XPS spectra. It appears that the peak of $\mathrm{O} 1 \mathrm{~s}$, centred at $532.5 \mathrm{eV}$ for the $\mathbf{T E}$ sample, is displaced to $531.6 \mathrm{eV}$ for TEO (Fig. 2). The position of the peak remains unchanged even after the PCN-H $\mathrm{H}_{2} \mathrm{O}_{2}$ adduct is heated up to $300{ }^{\circ} \mathrm{C}$. The XPS spectrum of TEO400 clearly indicates that the $\mathrm{O} 1 \mathrm{~s}$ maximum returns to the same value of binding energy as that of the starting material (Fig. 2). The similar shift of the $\mathrm{O} 1 \mathrm{~s}$ peak was earlier reported for $\mathrm{H}_{2} \mathrm{O}_{2}$-treated carbon nitrides $[46,47]$, however, the assignment of these oxygen-containing moieties is a controversial matter. Li et al. [47], who subjected PCN to hydrothermal treatment in $\mathrm{H}_{2} \mathrm{O}_{2}$ solution, attributed the appearance of the peak at $531.6 \mathrm{eV}$ to the formation of $\mathrm{N}-\mathrm{C}-\mathrm{O}$ or adsorbed $\mathrm{O}_{2}$ species. Liu et al. [46] suggested that the cause was an O-doping of the heptazine skeleton. The absence of any noticeable changes in the chemical states of $\mathrm{C}$ and $\mathrm{N}$ atoms in the $\mathrm{PCN}-\mathrm{H}_{2} \mathrm{O}_{2}$ samples prepared in this work compared to the thermally etched PCN, and the fact that the adsorbed oxygen is expected to appear in XPS spectra at about $532 \mathrm{eV}$ [49] suggest to hold on to the earlier proposed hypothesis [41]. The reaction of melamine with hydrogen peroxide produces the crystalline MHP adduct [50,51], whose structure is reported by Chernyshov et al. [52]. In a very similar way, $\mathrm{H}_{2} \mathrm{O}_{2}$ can interact with the surface carbon nitride species [41]. Here, we corroborate this hypothesis by 
comparing the O 1s XPS data obtained for the crystalline MHP complex, whose structure is confirmed by the XRD measurement (Fig. S4), and the $\mathrm{PCN}-\mathrm{H}_{2} \mathrm{O}_{2}$ samples (Fig. 2). The O 1s peak of MHP complex is centred at $531.3 \mathrm{eV}$ nearly coinciding with the $\mathrm{O}$ 1s maximum found for the TEO, TEO200, and TEO300 samples; however, the contribution of other oxygen species also present in PCN causes its shift to 531.5-531.6 eV (Fig. 2, Table 1). A drastic reduction of the oxygen content observed for TEO300 can be attributed to the elimination of a greater part of bonded $\mathrm{H}_{2} \mathrm{O}_{2}$, although the fact that the position of the $\mathrm{O} 1 \mathrm{~s}$ maximum remains unchanged could indicate the presence of small quantities of $\mathrm{H}_{2} \mathrm{O}_{2}$ retained in the material. Thus, considering the surface elemental composition and the position of the $\mathrm{O} 1 \mathrm{~s}$ maximum, one can conclude that the reaction of PCN with $\mathrm{H}_{2} \mathrm{O}_{2}$ produces a $\mathrm{PCN}-\mathrm{H}_{2} \mathrm{O}_{2}$ adduct stable in air up to $200{ }^{\circ} \mathrm{C}$.

\section{Solid-state MAS ${ }^{1} \mathrm{H},{ }^{13} \mathrm{C}$, and ${ }^{1} \mathrm{H}-{ }^{13} \mathrm{C}$ CPMAS NMR studies}

The chemical shifts of the two maxima at 156.7 and $165.0 \mathrm{ppm}$ on the ${ }^{13} \mathrm{C}$ MAS NMR spectra correspond to carbon atoms bonded to three nitrogen atoms of the aromatic carbon nitride structural units $\left(\mathrm{C}_{i}\right)$ and to those bearing non-polymerised $\mathrm{NH}_{2}$ and partially polymerised $\mathrm{NH}$ fragments $\left(\mathrm{C}_{e}\right)$, respectively (Fig. 3, Fig. 4A). This is confirmed by the ${ }^{1} \mathrm{H}_{-}{ }^{13} \mathrm{C}$ CPMAS NMR, where the signal at $165.0 \mathrm{ppm}$ is significantly enhanced (Fig. 4B).

\section{FIGURE 3}

The ${ }^{13} \mathrm{C}$ MAS NMR peak positions do not suffer any noticeable displacements after the material is reacted with $\mathrm{H}_{2} \mathrm{O}_{2}$ or subsequently heated (Fig. 4A). The $\mathrm{C}_{i}$ to $\mathrm{C}_{e}$ integrated area ratio of 1.0 is also constant for all of the tested samples (Table 2). It confirms that the bulk structure of PCN is retained and the relative quantity of the uncondensed units is also unchanged, in spite of the procedures the material underwent.

\section{FIGURE 4}

\section{TABLE 2}

One of the characteristic features of $\mathrm{PCN}$ is a strong hydrogen bonding of $\mathrm{NH}_{2}$ and $\mathrm{NH}$ functionalities to $\mathrm{N}$ atoms of another heptazine [27,53]. There is still no consensus in the assignation of the most intense ${ }^{1} \mathrm{H}$ maximum in polymerised $\mathrm{C}_{3} \mathrm{~N}_{4}$ heptazines. On the basis of theoretical calculations, it is suggested that the peak at about $4.3 \mathrm{ppm}$ corresponds to the free amino-groups of PCN [54]. However, the alternative view, founded on the experimental data 
collected from polymerised heptazine (melon), attributes it to the protons of hydrogen-bonded water molecules [53,55]. The decrease of the intensity of this maximum under in-situ heat treatment at $150{ }^{\circ} \mathrm{C}$ in NMR apparatus is in accord with the above hypothesis [56]. Although adsorbed water is not a part of the structural PCN unit, the type of its interaction with PCN gives information about the state of the surface species in the photocatalysts. A relatively narrow maximum, of $340 \mathrm{~Hz}$ of half-width at half-maximum (HWHM) of the $\mathrm{H} 1$ peak centred at approximately $4.5 \mathrm{ppm}$ observed for the TE sample is noticeably broadened to 548 and $520 \mathrm{~Hz}$ for the TEO and TEO200 samples, respectively. This could indicate the involvement of water adsorption sites in hydrogen bonding with other species present in $\mathrm{PCN}-\mathrm{H}_{2} \mathrm{O}_{2}$ (Fig. 4C, Fig. S5AC, Table 2). For TEO300 and TEO400 the corresponding HWHM value is reduced again (Fig. S5D,E, Table 2). This finding suggests that the modification of water adsorption sites in TEO and TEO200 is due to the changes in the hydrogen bonding network caused by the attachment of hydrogen peroxide molecules to the amino-groups and heptazine nitrogen atoms (Fig. 3). On the other hand, TEO400 having its melon layers well-separated and hydrogen bonding between them significantly reduced demonstrates a narrow peak at $4.5 \mathrm{ppm}$, which can be attributed to the adsorption of water molecules on well-defined surface sites.

The defect sites in PCN, i.e. $\mathrm{NH}_{2}$ and $\mathrm{NH}$ species, according to Syefarth et al. [55], reveal themselves at 10 and $9.5 \mathrm{ppm}$, respectively, and a very similar range of chemical shifts, from 8.4 to 10.9, was also proposed by Hu et al [54]. (Fig. 3). On the ${ }^{1} \mathrm{H}$ MAS NMR spectrum of the MHP adduct, the main peak is centred at $10.9 \mathrm{ppm}$, and it can be assigned to the protons of $\mathrm{H}_{2} \mathrm{O}_{2}$ as well as to the developed hydrogen bonding in a melamine peroxosolvate crystal, where one molecule of $\mathrm{H}_{2} \mathrm{O}_{2}$ is able to interact with six melamine molecules [52] (Fig. S6). The much lower concentration of $\mathrm{H}_{2} \mathrm{O}_{2}$ in the $\mathrm{PCN}-\mathrm{H}_{2} \mathrm{O}_{2}$ materials and interference of the protons of the $\mathrm{NH}-$ and $\mathrm{NH}_{2}$-groups make it difficult to fully understand the contribution of this peak to the spectra. The deconvolution of the spectra by three Lorentz functions centred at about of $4.5(\mathrm{H} 1), 9.4(\mathrm{H} 2)$, and $1.0(\mathrm{H} 3) \mathrm{ppm}$ indicates that the peak at $9.4 \mathrm{ppm}$ for the TEO and TEO200 samples is significantly broadened and its contribution to the spectra is greater than for the other PCN samples (Fig. S5, Table 2). This finding can be attributed to the protons of $\mathrm{H}_{2} \mathrm{O}_{2}$ bonded to carbon nitride and to the displacement of the chemical shift maxima of the $\mathrm{NH}_{2}$ moieties, due to the formation of hydrogen bonding between amino-groups and heptazine nitrogens mediating $\mathrm{H}_{2} \mathrm{O}_{2}$ 
(Fig. 3). The peak at approximately $1.0 \mathrm{ppm}(\mathrm{H} 3)$ could be assigned to $\mathrm{H}_{2} \mathrm{O}$ adsorbed on isolated basic sites of carbon nitride as it occurs on the surface of basic oxides [57].

\section{Electronic structure}

The band gap (BG) of the thermally etched carbon nitride (TE) is $2.76 \mathrm{eV}$ (Fig. 5A, Table 1), which is close to the value reported earlier for the same type of photocatalysts [39]. The valence band (VB) of this sample is positioned at $1.59 \mathrm{eV}$, lower than that of the bulk PCN synthesised via the same process [38] (Fig. 5A inset, Table 1). The treatment of the thermally etched polymeric $\mathrm{C}_{3} \mathrm{~N}_{4}$ with $\mathrm{H}_{2} \mathrm{O}_{2}$ does not change the $\mathrm{BG}$ value significantly, although a new absorption edge at lower energies of approximately $2.19 \mathrm{eV}$ appears (Fig. 5B, Table 1). This could be explained by the formation of midgap states in the electronic structure of the $\mathrm{PCN}-\mathrm{H}_{2} \mathrm{O}_{2}$ adduct, which is also deduced from the reduced value of its VB (Fig. 5B, inset). The heat treatment of TEO causes a slight decrease in the concentration of oxygen belonging to the bonded $\mathrm{H}_{2} \mathrm{O}_{2}$ (Table 1). Nevertheless, the absorption edge at $2.16 \mathrm{eV}$ is retained (Fig. 5C, Table 1). Moreover, it is obvious that the sample undergoes some other changes, as its BG value decreases to $2.67 \mathrm{eV}$, while its VB has a potential of $1.52 \mathrm{eV}$ (Fig. 5C inset, Table 1). Considering the evidenced by NMR studies strong hydrogen bonding in the TEO and TEO200 samples, it can be hypothesised that the changes in their electronic structures are due to a strong interaction between adjacent carbon nitride units which interact with $\mathrm{H}_{2} \mathrm{O}_{2}$. The increase of thermal treatment temperature up to $300{ }^{\circ} \mathrm{C}$ results in an almost complete disappearance of the midgap absorption edge observed for the above discussed samples, and in the BG value equal to that of the parent material, TE (Fig. 5D, Table 1). Notably, the VB position maintains the same value of $1.52 \mathrm{eV}$ (Fig. 5D inset, Table 1). The shift of the (002) diffraction maximum observed for TEO400 (Fig. 1) could be related to its thermal etching at high temperatures in an oxidative atmosphere. Indeed, the increase of the BG and VB values is in accord with this hypothesis as the same effect of thermal etching on the BG was also observed elsewhere [39].

\section{FIGURE 5}

The PL spectra registered after the excitation at $365 \mathrm{~nm}$ show photoluminescence quenching for the PCN- $\mathrm{H}_{2} \mathrm{O}_{2}$ samples, which can be explained by the favoured charge separation on strongly 
hydrogen bonded carbon nitride units. In addition, the appearance of a new PL band for the PCN$\mathrm{H}_{2} \mathrm{O}_{2}$ adducts can be noticed (Fig. S7).

\section{$\mathbf{N}_{2}$ physisorption}

All the prepared samples show the adsorption isotherms of IV type with a hysteresis loop of a mixed $\mathrm{H} 3-\mathrm{H} 4$ type corresponding to mesoporous materials with broad pore-size distribution (Fig. S8). The porous structure itself barely changes after the $\mathrm{PCN}-\mathrm{H}_{2} \mathrm{O}_{2}$ adduct is formed and the subsequent thermal treatment is applied, however, the differences in SSA values are drastic (Fig. S8, Table 1). The SSA of TEO is reduced to $70 \mathrm{~m}^{2} \mathrm{~g}^{-1}$ compared to $94 \mathrm{~m}^{2} \mathrm{~g}^{-1}$ of TE (Table 1). The SSAs of TEO200 and TEO300 are smaller, i.e. 23 and $30 \mathrm{~m}^{2} \mathrm{~g}^{-1}$, respectively (Table 1, Fig. S8). It has already been proposed while discussing the XRD and DRS data that TEO400 shows the features characteristic of thermally etched carbon nitride. Indeed, the increase of its SSA value up to $168 \mathrm{~m}^{2} \mathrm{~g}^{-1}$ unambiguously confirms this supposition (Table 1. Fig. S8).

\section{TPD-MS analysis of the $\mathrm{PCN}$ and $\mathrm{PCN}-\mathrm{H}_{2} \mathrm{O}_{2}$ samples}

The MS analysis of the volatile substances evolved during the thermal treatment of the TE and TEO samples under inert atmosphere shows the presence of 18 amu attributed to adsorbed or chemically bonded $\mathrm{H}_{2} \mathrm{O}$ in PCN (Fig. S9A). For the TE sample water removal ends at about 200 ${ }^{\circ} \mathrm{C}$, while the additional smaller peak observed for TEO around $300{ }^{\circ} \mathrm{C}$ could be due to $\mathrm{H}_{2} \mathrm{O}$ formed in the result of the bonded $\mathrm{H}_{2} \mathrm{O}_{2}$ decomposition (Fig. S9A inset). The materials release $\mathrm{CO}_{2}(44 \mathrm{amu})$ at different temperatures that might be attributed to the modification of the basic adsorption surface sites in the $\mathrm{PCN}-\mathrm{H}_{2} \mathrm{O}_{2}$ or to the release of $\mathrm{O}_{2}$ during the $\mathrm{PCN}-\mathrm{H}_{2} \mathrm{O}_{2}$ heating, which can partially oxidise surface carbon nitride species (Fig. S9B). Three more gaseous products with mass numbers 32,30 , and 28 amu, respectively assigned to $\mathrm{O}_{2}, \mathrm{NO}$, and $\mathrm{N}_{2}$, are detected only for the TEO sample (Fig. S9C-E). These species are produced as a result of the bonded $\mathrm{H}_{2} \mathrm{O}_{2}$ decomposition and the oxidation of the surface carbon nitride groups (Fig. S9C-E). The findings corresponding to the $\mathrm{O}_{2}$ and $\mathrm{N}_{2}$ generation during the adduct decomposition are consistent with the proposed thermal degradation pathway of another $\mathrm{H}_{2} \mathrm{O}_{2}$ complex compound urea-hydrogen peroxide adduct [58]. Summarizing, the $\mathrm{PCN}-\mathrm{H}_{2} \mathrm{O}_{2}$ is likely to contain a weakly bonded hydrogen peroxide, which decomposes at temperatures below $200{ }^{\circ} \mathrm{C}$ producing $\mathrm{H}_{2} \mathrm{O}$ and 
$\mathrm{O}_{2}$ but also strongly bonded peroxo species, whose thermal degradation gives rise to oxidation of the surface $\mathrm{C}-\mathrm{NH}_{\mathrm{x}}$-groups producing gaseous $\mathrm{NO}, \mathrm{CO}_{2}$ and $\mathrm{N}_{2}$.

\section{HMF partial photo-oxidation to FDC under UV-irradiation}

The adsorption capacity of the photocatalysts did not exceed $1 \%$ of the initial HMF concentration. Photolyses of the substrate and of the principal reaction product were determined for the used photocatalytic set-up earlier [39]. The possible release of $\mathrm{H}_{2} \mathrm{O}_{2}$ by the $\mathrm{PCN}-\mathrm{H}_{2} \mathrm{O}_{2}$ photocatalysts into water suspensions was tested. No $\mathrm{H}_{2} \mathrm{O}_{2}$ was found in the aqueous suspension of photocatalysts when it was heated up to $50{ }^{\circ} \mathrm{C}$, while negligible quantities, not exceeding 6.6 $\mu$ mol of $\mathrm{H}_{2} \mathrm{O}_{2}$ per $1 \mathrm{~g}$ of the $\mathrm{PCN}-\mathrm{H}_{2} \mathrm{O}_{2}$ adduct, were released at boiling point.

\section{FIGURE 6}

Expectedly, under UV irradiation the thermally etched PCN (TE) shows high HMF conversion approaching $47 \%$, which is close to that reported elsewhere [39]. Also, it is the most active sample among all the tested ones (Fig. 6A, Table 3). The treatment of TE with hydrogen peroxide results in almost three times less active photocatalyst (TEO), due probably to its reduced SSA (70 $\mathrm{m}^{2} \mathrm{~g}^{-1}$ ) (Fig. 6A, Table 3) and to the blockage of certain carbon nitride surface sites to which $\mathrm{H}_{2} \mathrm{O}_{2}$ is attached. Despite the further reduction of the SSA observed for the thermally treated PCN- $\mathrm{H}_{2} \mathrm{O}_{2}$ adducts at $200{ }^{\circ} \mathrm{C}\left(\right.$ TEO200) and $300{ }^{\circ} \mathrm{C}$ (TEO300), the HMF conversion degree barely changes (Fig. 6A). The explanation of this finding could be found in the improved charge transfer and charge separation occurring on strongly hydrogen bonded melon units. The activity of the TEO400 sample, however, was found higher than that of TEO300, but still less significant than that of TE (Fig. 6A). Although the SSA of TEO400 is the highest among all of the tested materials, this property does not exclusively determine the photocatalytic performance of carbon nitride materials. Considering other differences in the TE and TEO400 features, the only one able to explain the decreased photoactivity is the low surface oxygen content and lower $\mathrm{O} 1 \mathrm{~s}$ binding energy value of the latter (Table 1). It might be an indication of a higher strength of TEO400 basic sites, hence the presence of strongly bonded adsorbed oxygen species [59], whose removal from the surface in a form of radicals is hindered.

TABLE 3 
The highest amount of FDC produced during the photocatalytic HMF conversion was observed for the TE sample, while for TEO300 this value was the lowest one (Fig. 6B, Table 3). Despite the reduced conversion degree, TEO demonstrates significantly improved selectivity for the FDC production reaching $71 \%$ at $20 \%$ of HMF conversion, while the corresponding value for the thermally etched PCN is only 40\% (Table 3, Fig. 6C). Moreover, the selectivity is also maintained on a nearly the same level throughout the reaction (Fig. 6C). Subjecting the $\mathrm{PCN}-\mathrm{H}_{2} \mathrm{O}_{2}$ adduct to thermal treatment at $200{ }^{\circ} \mathrm{C}$ ( $\mathbf{T E O 2 0 0}$ ) does not affect the selectivity to FDC formation (Fig. 6C). For the TEO300 and TEO400 samples, the selectivity is very similar to that of TE (Fig. 6C). This can be attributed to the drop in the content of oxygen corresponding to the presence of $\mathrm{H}_{2} \mathrm{O}_{2}$ in the PCN- $\mathrm{H}_{2} \mathrm{O}_{2}$ adduct (Table 1). The relation of selectivity to FDC formation versus HMF conversion represented in Figure 6D indicates that the $\mathrm{PCN}-\mathrm{H}_{2} \mathrm{O}_{2}$ adduct samples have higher selectivity to FDC production at the same conversion extent than TE, TEO300 and TEO400 (Table 3). For the TEO and TEO200 photocatalysts, similar values of the rates of $\mathrm{HMF}$ conversion and FDC formation are obtained, indicating that HMF to FDC oxidation is the primary process occurring in the irradiated suspension (Table 3). For the other materials (TE, TEO300, TEO400) the respective values differ by more than a factor of 2 because parallel reactions take place (Table 3). There are several factors responsible for HMF to FDC selectivity being below $100 \%$. Once FDC is produced in the reaction suspension, it is slowly photolysed to FFA (Fig. S10). Another factor contributing to the selectivity loss, especially in case of the TE, TEO300 and TEO400 samples, is the direct oxidation of HMF to aliphatic carboxylic acids, detected but not identified in the present work.

The sample prepared by the thermal etching of the $\mathrm{PCN}-\mathrm{H}_{2} \mathrm{O}_{2}$ adduct at $450{ }^{\circ} \mathrm{C}$ ( TEO450) has also been studied. Although it shows an HMF conversion degree higher than that of TE, it does not demonstrate any improvement of the selectivity (Fig. S11). The alternative method of $\mathrm{H}_{2} \mathrm{O}_{2}-$ modification via refluxing the suspension of $\mathrm{H}_{2} \mathrm{O}_{2}$ and $\mathbf{T E}$ resulted in the formation of the TEO_R photocatalyst having mild reaction rate and selectivity of about $60 \%$, which is lower than that observed for TEO (Fig. S11).

The recoverability of the TEO photocatalyst was tested in three consecutive reaction cycles under UV irradiation. TEO maintains the same conversion degree and the selectivity to FDC formation 
equal to $19-21 \%$ and $68-82 \%$, respectively, thus proving itself as an efficient photocatalyst for the partial photo-assisted HMF oxidation (Fig. S12).

\section{HMF partial photo-oxidation to FDC under solar light}

$\mathrm{PCN}$ is an attractive photocatalyst for reactions occurring under solar light, due to the electronic structure which allows its activation under visible-light irradiation. Unsurprisingly, the reaction rate under sunlight is significantly improved for all of the tested materials with respect to that achieved under the UV lamps, which is attributed to the higher UV photon flux of the outdoor irradiation (Fig. 7A, Table 3). The most active TE sample is capable of oxidising almost all of the substrate within the reaction time, while other photocatalysts show degrees of conversion nearly twice increased with respect to those obtained under the UV-source used (Fig. 7A, Table 3). The comparison of the cumulative energies entering the UV and solar-light reactors shows that the photocatalytic activity is almost directly proportional to the energy of irradiation with wavelengths from 315 to $400 \mathrm{~nm}$ (Table 3). However, the performance of TEO200 stands aside of the common trend, which is most probably due to its narrower BG with respect to those of the other tested photocatalysts (Fig. 7A, Table 3). The concentration of FDC, for the TE and TEO400 samples, increases with the cumulative energy up to about $1.65 \mathrm{~kJ}$, after which a plateau is observed (Fig. 7B). This finding can be explained by considering the high extent of conversion achieved in the presence of these samples because the product itself becomes a target for photoproduced radical species after most of the substrate is oxidised. As far as the selectivity is concerned, no significant differences can be noticed between the results obtained under UV irradiation and solar light (Fig. 7C). The selectivity toward FDC approaches 100\% at low HMF conversion values in the presence of the TEO sample, while it ranges between 70 to $80 \%$ for moderate and high conversions in the cases of the TEO and TEO200 samples. These figures are higher than the corresponding ones attained by the thermally etched PCN (TE), TEO300 and TEO400 samples (Fig. 7D).

\section{FIGURE 7}

Additional tests to prove the effectiveness of the TEO sample for the conversion of HMF to FDC at enhanced concentrations of the substrate $(1$ and $2 \mathrm{mM})$ were performed. The quantity of HMF converted is found to be in a nearly direct dependency from the initial HMF concentration (Fig. 
8A). TEO converts $15.6 \mu \mathrm{mol}$ of HMF when the initial substrate concentration is $0.5 \mathrm{mM}$, while 30.5 and $56.3 \mu \mathrm{mol}$ are converted when the initial concentrations are 1.0 and $2.0 \mathrm{mM}$, respectively (Fig. 8A). Figure 8B shows that the selectivity to FDC decreases by increasing HMF initial concentration (Fig. 8B), however, it appears to be on the same level when plotted against the quantity of HMF reacted (Fig. 8C).

\section{FIGURE 8}

A dramatic effect on the selectivity of the photo-oxidation of HMF to FDC, consequent to the formation of the $\mathrm{PCN}-\mathrm{H}_{2} \mathrm{O}_{2}$ adduct, could be attributed to the type of interaction of the substrate molecules with some carbon nitride surface sites. In a previous study on the HMF photo-oxidation in the presence of thermally exfoliated PCN, the selectivity to FDC up to $75 \%$ was obtained in the organic solvent [39], and this value is close to that found in the present work for the $\mathrm{PCN}-\mathrm{H}_{2} \mathrm{O}_{2}$ adducts in aqueous medium. The presence of water could have a detrimental effect on the reaction selectivity. Indeed, the test for hydroxyl radicals generation by TA method confirms their formation, and in particular that TE produces higher quantities of ${ }^{\circ} \mathrm{OH}$ than TEO (Fig. S13). It is commonly accepted that $\mathrm{PCN}$ cannot form ${ }^{\circ} \mathrm{OH}$ radicals by directly oxidising water with photogenerated holes, whilst it is possible by the action of photo-generated electrons mediating $\mathrm{H}_{2} \mathrm{O}_{2}$ formation [60]. Nonetheless, we have not observed the photocatalytic production $\mathrm{H}_{2} \mathrm{O}_{2}$ in the absence of the substrate. Another pathway could also be considered: the non-polymerised $\mathrm{C}_{3} \mathrm{~N}_{4}$ species bearing Brønsted basic sites, i.e. amino-groups, form hydrogen bonds in water suspension, giving positively charged $-\mathrm{NH}_{3}{ }^{+}$surface moieties [61] (Fig. 9A). The coordination of water in this way allows it being attacked by the photo-generated holes ripping off electrons from the $\mathrm{H}_{2} \mathrm{O}$ molecules and forming ${ }^{\circ} \mathrm{OH}$ radicals, which are not produced on the polymerised aromatic units of carbon nitride, due to the low potential of its VB [28] (Fig. 9A). For the thermally etched PCN photocatalyst, the $\mathrm{NH}_{2}$ functionalities, where the produced ${ }^{\circ} \mathrm{OH}$ radicals are localized, are accessible for the interaction with $\mathrm{HMF}$, which can be attached to the uncondensed carbon nitride species in a similar way as it was proposed for an aromatic compound [41]. The reaction of HMF with hydroxyl radical leads to the ring opening and the formation of aliphatic intermediates, observed but not studied in this work, thus reducing the selectivity of the photo-oxidation reaction toward the formation of FDC (Fig. 9B). On the other hand, $\mathrm{H}_{2} \mathrm{O}_{2}$ blocks the amino-groups of the $\mathrm{PCN}-\mathrm{H}_{2} \mathrm{O}_{2}$ adducts, thus creating a steric hindrance for the HMF molecule interaction with the 
carbon nitride surface sites (Fig. 9C). Therefore, the $\mathrm{PCN}-\mathrm{H}_{2} \mathrm{O}_{2}$ samples favour higher selectivity to FDC formation, whilst the HMF conversion rates appear lower, due to the absence of hydroxyl radicals action and to the smaller SSAs of these photocatalysts (Fig. 9C).

\section{FIGURE 9}

\section{Conclusions}

PCN reacts with $\mathrm{H}_{2} \mathrm{O}_{2}$ producing $\mathrm{PCN}-\mathrm{H}_{2} \mathrm{O}_{2}$ adduct stable up to $200{ }^{\circ} \mathrm{C}$ in air. The formed material does not release $\mathrm{H}_{2} \mathrm{O}_{2}$ into the suspension in aqueous medium and under irradiation, thus ensuring its usability for photocatalytic applications. The result of $\mathrm{H}_{2} \mathrm{O}_{2}$ bonding to the carbon nitride partially polymerised and non-polymerised sites is the development of hydrogen bonding network within the material. The formation of the adduct is also responsible for the blockage of $\mathrm{NH}_{2}$ functional groups, which are detrimental for the selective partial photocatalytic oxidation of HMF to FDC. The bonded $\mathrm{H}_{2} \mathrm{O}_{2}$ creates a steric hindrance for the HMF interaction with aminogroups, where ${ }^{\circ} \mathrm{OH}$ radicals, driving to furanic ring opening and hence unselective oxidation of the substrate, are probably localized. The elimination from the reaction process of the pathway involving the action of hydroxyl radicals leads to the enhancement of the selectivity toward the FDC production under outdoor illumination from $45 \%$ to $88 \%$ at $20 \%$ of $\mathrm{HMF}$ conversion. Moreover, the prepared $\mathrm{PCN}-\mathrm{H}_{2} \mathrm{O}_{2}$ adduct photocatalyst proved itself recoverable and efficient in the solar light assisted conversion of HMF even at high initial concentrations of the substrate. The present work has underlined the importance of the modification of the surface species of PCN for its improved performance in partial photo-oxidation reactions.

\section{Conflicts of interest}

There are no conflicts to declare.

\section{Acknowledgements}

We gratefully acknowledge financial support from the Spanish MINECO (MAT2013-40950-R, MAT2016-78155-C2-1-R, CTQ2014-52956-C3-1-R, and Severo Ochoa PhD grant BP-14-029 to M.I.) and FEDER. IK acknowledges financial support from Ministry of Education and Science of 
the Russian Federation (grant No 4.9722.2017/8.9) and grateful for the support by Act 211 Government of the Russian Federation, contract № 02.A03.21.0011.

\section{Notes and references}

1 S. Suganuma, K. Nakajima, M. Kitano, D. Yamaguchi, J. Am. Chem. Soc. 130 (2008) $12787-12793$

2 J.N. Chheda, Y. Roman-Leshkov, J.A. Dumesic, Green Chem. 9 (2007) 342-350.

3 G.Z. Papageorgiou, D.G. Papageorgiou, Z. Terzopoulou, D.N. Bikiaris, Eur. Polym. J., 83 (2016) 202-229.

4 A.F. Sousa, C. Vilela, A.C. Fonseca, M. Matos, C.S.R. Freire, G.-J.M. Gruter, J.F.J. Coelho, A.J.D. Silvestre, Polym. Chem. 6 (2015) 5961-5983.

5 I. Delidovich, P.J.C. Hausoul, L. Deng, R. Pfützenreuter, M. Rose, R. Palkovits, Chem. Rev. 116 (2016) 1540-1599.

6 A.S. Amarasekara, D. Green, L.D. Williams, Eur. Polym. J. 45 (2009) 595-598.

7 T. Xiang, X. Liu, P. Yi, M. Guo, Y. Chen, C. Wesdemiotis, Y. Pang, Polym. Int. 62 (2013) $1517-1523$.

8 J.M.R. Gallo, D.M. Alonso, M.A. Mellmer, J.A. Dumesic, Green Chem. 15 (2013) 85-90.

9 X. Tong, Y. Ma, Y. Li, Appl. Catal. A: Gen. 385 (2010) 1-13.

10 I. Sadaba, Y.Y. Gorbanev, S. Kegnæs, S. Reddy, ChemCatChem. 5 (2013) 284-293.

11 C. Carlini, P. Patrono, A. Maria, R. Galletti, Appl. Catal. A: Gen. 289 (2005) 197-204.

12 J. Nie, J. Xie, H. Liu, J. Catal. 301 (2013) 83-91.

13 F. Neat, N. Petrea, R. Petre, V. Somoghi, M. Florea, V.I. Parvulescu, Catal. Today. 278 (2016) 66-73.

14 M. Chatterjee, T. Ishizaka, A. Chatterjee, H. Kawanami, Green Chem. 19 (2017) 13151326.

15 Y. Shiraishi, T. Hirai, J. Photochem. Photobiol. C: Photochem. Rev. 2008, 9, 157-170.

16 X. Lang, W. Ma, C. Chen, H. Ji, J. Zhao, Acc. Chem. Res. 47 (2014) 355-363.

17 V. Augugliaro, G. Camera-roda, V. Loddo, L. Palmisano, J. Soria, S. Yurdakal, J. Phys. Chem. Lett. 6 (2015) 1968-1981. 
G. Palmisano, A. Albini, G. Marcì, L. Palmisano, D. Ravelli, RSC Energy Environ. Series. 15 (2016) 303.

19 X. Lang, J. Zhao, Chem Soc Rev. 43 (2014) 473-486.

20 J. Kou, C. Lu, J. Wang, Y. Chen, Z. Xu, R.S. Varma, Chem. Rev. 117 (2017) 1445-1514.

21 D.W. Wakerley, M.F. Kuehnel, K.L. Orchard, K.H. Ly, T.E. Rosser, E. Reisner, Nature Energ. 2 (2017) 17021.

22 S.-H. Li, S. Liu, J.C. Colmenares, Y.-J. Xu, Green Chem., 18 (2016) 594-607.

23 G. Chatel, S. Valange, R. Behling, J.C. Colmenares, ChemCatChem. 9 (2017) 2615-2621.

24 L. Ozcan, P. Yalcin, O. Alagoz, S. Yurdakal, Catal. Today. 281 (2017) 205-213.

25 S. Yurdakal, B. S. Tek, O. Alagöz, V. Augugliaro, V. Loddo, G. Palmisano, L. Palmisano, ACS Sustain. Chem. Eng. 1 (2013) 456-461.

26 I. Krivtsov, M. Ilkaeva, E. Salas-Colera, Z. Amghouz, J.R. García, E. Díaz, S. Ordoñez, S. Villar-Rodil, J. Phys. Chem. C. 121 (2017) 6770-6780.

27 F.K. Kessler, Y. Zheng, D. Schwarz, C. Merschjann, W. Schnick, X. Wang, M.J. Bojdys, Nature Mater., 2017, 17030.

28 X. Wang, K. Maeda, A. Thomas, K. Takanabe, G. Xin, J.M. Carlsson, K. Domen, M. Antonietti, Nat. Mater. 8 (2008) 76-80.

29 X. Dai, M. Xie, S. Meng, X. Fu, S. Chen, Appl. Catal. B: Environ. 158-159 (2014) 382-390.

30 F. Su. S. C. Mathew, G. Lipner, X. Fu, M. Antonietti, S. Blechert, X. Wang, J. Am. Chem. Soc. 123 (2010) 16299-16301.

31 J. Xu, L. Luo, G. Xiao, Z. Zhang, H. Lin, X. Wang, J. Long, ACS Catal. 4 (2014) 33023306.

32 S. Verma, R.B.N. Baig, M.N. Nadagouda, R.S. Varma, ACS. Sustain. Chem. Eng. 4 (2016) 1094-1098.

33 X. Chen, J. Zhang, X. Fu, M. Antonietti, X. Wang, J. Am. Chem. Soc.. 131 (2009) 1165811659.

34 X.-H. Li, X. Wang, M. Antonietti, ACS Catal. 2 (2012) 2082-2086.

35 X.-H. Li, J.-S. Chen, X. Wang, J. Sun, M. Antonietti, J. Am. Chem. Soc. 133 (2011) 80748077.

36 Z. Ding, X. Chen, M. Antonietti, X. Wang, ChemSusChem. 4 (2011) 274-281. 
37 B. Long, Z. Ding, X. Wang, ChemSusChem. 6 (2013) 2074-2078.

38 M. Bellardita, E.I. García-López, G. Marcì, I. Krivtsov, J.R. García, L. Palmisano, Appl. Catal. B: Environ. 220 (2018) 222-233.

39 I. Krivtsov, E.I. García-López, G. Marcì, L. Palmisano, Z. Amghouz, J.R. García, E. Díaz, S. Ordóñez, Appl. Catal., B: Environ. 204 (2017) 430-439.

40 A. Akhundi, E.I. García-López, G. Marcì, A. Habibi-Yangjeh, L. Palmisano, Res. Chem. Intermed. 43 (2017) 5153-5168.

41 M. Ilkaeva, I. Krivtsov, E.V. Bartashevich, S. Khainakov, J.R. García, E. Díaz, S. Ordóñez, Green Chem. 19 (2017) 4299-4304.

42 K. Wang, Q. Li, B. Liu, B. Cheng, W. Ho, J. Yu, Appl. Catal. B: Environ. 176-177 (2015) 44-52.

43 P. Niu, L. Zhang, G. Liu, H.-M. Chen, Adv. Funct. Mater. 22 (2012) 4763-4770.

44 V. Augugliaro, E.I. García-López, V. Loddo, S. Malato-Rodriguez, I. Maldonado, G. Marcì, R. Molinari, L. Palmisano, Solar Energy. 79 (2005) 402-408.

45 T. Hirakawa, Y. Nosaka, Langmuir, 18 (2002) 3247-3254.

46 S. Liu, D. Li, H. Sun, H. Ming, M. O. Tadé, S. Wang, J. Colloid Interface Sci., 468 (2016) 176-182.

47 J. Li, B. Shen, Z. Hong, B. Lin, B. Gao, Y. Chen, Chem. Comm. 4 (2012) 12017-12019.

48 F. Dong, Y. Li, Z. Wang, W. Ho, Appl. Surf. Sci. 358 (2015) 393-403.

49 B. Marchon, J. Carrazza, H. Heinemann, G. A. Somorjai, Carbon. 26 (1988) 507-514.

50 T. Nagaishi, M. Matsumoto, S. Yoshigana, J. Therm. Anal. Calorim. 36 (1990) 55-60.

51 G. Chehardoli, M.A. Zolfigol, Phosphorus, Sulfur Silicon Relat. Elem. 185 (2010) 193-203.

52 I.Yu. Chernyshov, M.V. Vener, P.V. Prikhodchenko, A.G. Medveddev, O. Lev, A.V. Churakov, Cryst. Growth Des. 17 (2017) 214-220.

53 L. Seyfarth, J. Senker, Phys. Chem. Chem. Phys. 11 (2009) 3522-3531.

54 Y. Hu, Y. Shim, J. Oh, S. Park, S. Park, Y. Ishii, Chem. Mater. 29 (2017) 5080-5089.

55 L. Seyfarth, J. Seyfarth, B. V. Lotsch, W. Schnick, J. Senker, Phys. Chem. Chem. Phys. 12 (2010) 2227-2237.

56 W.J. Gammon, G.L. Hoatson, B.C. Holloway, R.L. Vold, A.C. Reilly, Phys. Rev. B. 68 (2003) 195401. 
57 M.A. Aramendía, J.A. Benítez, V. Borau, C. Jiménez, J.M. Marinas, J.R. Ruiz, F. Urbano, Langmuir. 15 (1999) 1192-1197.

58 R. Matyas, J. Selesovsky, V. Pelikan, M. Szala, S. Cudzilo, W. A. Trzcinsky, M. Gozin, Propellant. Explosiv. Pyrotech. 42 (2017) 198-203.

59 E. Díaz, E. Muñoz, A. Vega, S. Ordóñez, Ind. Eng. Chem. Res. 47 (2008) 412-418.

60 J. Liu, T. An, Z. Chen, Z. Wang, H. Zhou, T. Fan, D. Zhang, M. Antonietti, J. Mater. Chem. A. 5 (2017) 8933-8938.

61 S. Li, K. Su, Z. Li and B. Cheng, Green Chem. 18 (2016) 2122-2128. 


\section{Figure captions}

Figure 1. XRD patterns of the prepared $\mathrm{PCN}$ and $\mathrm{PCN}-\mathrm{H}_{2} \mathrm{O}_{2}$ samples.

Figure 2. XPS spectra of $\mathrm{O} 1$ s region of the $\mathrm{PCN}$ and $\mathrm{PCN}-\mathrm{H}_{2} \mathrm{O}_{2}$ samples.

Figure 3. Proposed model of interactions in the $\mathrm{PCN}-\mathrm{H}_{2} \mathrm{O}_{2}$ adduct.

Figure 4. (A) ${ }^{13} \mathrm{C}$ MAS NMR, (B) ${ }^{1} \mathrm{H}_{-}{ }^{13} \mathrm{C}$ CPMAS NMR and (C) ${ }^{1} \mathrm{H}$ MAS NMR spectra of the PCN and PCN- $\mathrm{H}_{2} \mathrm{O}_{2}$ samples.

Figure 5. DR spectra and XPS VB spectra (inset) of (A) TE, (B) TEO, (C) TEO200, (D) TEO300, and (E) TEO400.

Figure 6. (A) HMF and (B) FDC concentrations and (C) selectivity to FDC formation versus reaction time; (D) selectivity to FDC versus HMF conversion for the prepared photocatalysts under UV irradiation.

Figure 7. (A) HMF and (B) FDC concentrations and (C) selectivity to FDC formation versus reaction time; (D) selectivity to FDC versus HMF conversion for the prepared photocatalysts under solar light irradiation.

Figure 8. (A) HMF reacted and (B) selectivity to FDC versus cumulative energy; (C) selectivity to FDC formation versus amount of HMF reacted in the presence of the TEO photocatalyst under solar light irradiation at varying initial HMF concentrations.

Figure 9. (A) Hypothetical mechanism of hydroxyl radical formation on PCN basic sites; (B) proposed types of interaction and photo-oxidation of $\mathrm{HMF}$ on $\mathrm{PCN}$, and (C) on $\mathrm{PCN}-\mathrm{H}_{2} \mathrm{O}_{2}$. 


\section{Tables}

Table 1. XPS data, electronic structure and SSA values of the $\mathrm{PCN}$ and $\mathrm{PCN}-\mathrm{H}_{2} \mathrm{O}_{2}$ samples

\begin{tabular}{|c|c|c|c|c|c|c|}
\hline Sample & $\begin{array}{c}\text { XPS surface } \\
\text { composition [at\%] }\end{array}$ & $\begin{array}{c}\text { O 1s peak } \\
\text { position } \\
{[\mathrm{eV}]}\end{array}$ & BG [eV] & $\begin{array}{c}\mathrm{VB} \\
{[\mathrm{eV}]}\end{array}$ & $\mathrm{CB}[\mathrm{eV}]$ & SSA $\left[\mathrm{m}^{2} \mathrm{~g}^{-1}\right]$ \\
\hline TE & $\mathrm{C}_{42.3} \mathrm{~N}_{54.4} \mathrm{O}_{3.3}$ & 532.5 & 2.76 & 1.59 & -1.17 & 94 \\
\hline TEO & $\mathrm{C}_{40.8} \mathrm{~N}_{53.8} \mathrm{O}_{5.4}$ & 531.6 & $2.74 / 2.19$ & 1.44 & -1.30 & 70 \\
\hline TEO200 & $\mathrm{C}_{39.6} \mathrm{~N}_{55.8} \mathrm{O}_{4.6}$ & 531.6 & $2.67 / 2.16$ & 1.52 & -1.15 & 23 \\
\hline TEO300 & $\mathrm{C}_{41.0} \mathrm{~N}_{56.6} \mathrm{O}_{2.4}$ & 531.5 & 2.72 & 1.52 & -1.20 & 30 \\
\hline TEO400 & $\mathrm{C}_{41.7} \mathrm{~N}_{55.8} \mathrm{O}_{2.5}$ & 532.3 & 2.81 & 1.65 & -1.16 & 168 \\
\hline MHP & & 531.3 & & & & \\
\hline
\end{tabular}

Table 2. Solid state MAS NMR data obtained for the PCN and $\mathrm{PCN}-\mathrm{H}_{2} \mathrm{O}_{2}$ samples

\begin{tabular}{|c|c|c|c|c|c|}
\hline Samples & $\begin{array}{c}{ }^{13} \mathrm{C} \text { MAS NMR } \\
\mathrm{C}_{i} / \mathrm{C}_{e} \text { ratio }\end{array}$ & $\begin{array}{c}\text { Position of H1 } \\
\text { peak [ppm] }\end{array}$ & $\begin{array}{c}\text { HWHM of H1 } \\
\text { maximum }[\mathrm{Hz}]\end{array}$ & $\begin{array}{c}\text { HWHM of H2 } \\
\text { maximum }[\mathrm{Hz}]\end{array}$ & $\begin{array}{c}{ }^{1} \mathrm{H} \text { MAS NMR } \\
\text { H2/H1 ratio }\end{array}$ \\
\hline TE & 1.02 & 4.5 & 340 & 1100 & 0.63 \\
\hline TEO & 0.96 & 4.3 & 548 & 1624 & 1.06 \\
\hline TEO200 & 1.00 & 4.1 & 520 & 1888 & 1.91 \\
\hline TEO300 & 0.99 & 4.0 & 368 & & 748 \\
\hline TEO400 & 1.00 & 4.5 & 196 & 904 & 0.30 \\
\hline
\end{tabular}

Table 3. HMF initial conversion rate (r) under UV irradiation, HMF conversion and selectivity values under UV and natural solar light irradiation

\begin{tabular}{|c|c|c|c|c|c|c|c|c|c|c|}
\hline \multirow{3}{*}{ Sample } & \multicolumn{4}{|c|}{ UV } & \multicolumn{4}{|c|}{ Natural solar light } & \multicolumn{2}{|c|}{$\begin{array}{c}\text { Selectivity at } 20 \% \\
\text { of HMF } \\
\text { conversion [\%] }\end{array}$} \\
\hline & \multirow{2}{*}{$\begin{array}{l}\text { Initial HMF } \\
\text { conversion } \\
\text { rate } 10^{2} \\
{\left[\mathrm{mM} \mathrm{min}^{-1}\right]}\end{array}$} & \multirow{2}{*}{$\begin{array}{l}\text { Initial FDC } \\
\text { formation } \\
\text { rate } 10^{2} \\
{\left[\mathrm{mM} \mathrm{min}{ }^{-1}\right]}\end{array}$} & \multicolumn{2}{|c|}{$0.99 \mathrm{~kJ}(4 \mathrm{~h})$} & \multicolumn{2}{|c|}{$0.99 \mathrm{~kJ}(\sim 2 \mathrm{~h})$} & \multicolumn{2}{|c|}{$1.8 \mathrm{~kJ}(\sim 4 \mathrm{~h})$} & \multirow[t]{2}{*}{ UV } & \multirow{2}{*}{$\begin{array}{l}\text { Natural } \\
\text { solar light }\end{array}$} \\
\hline & & & $\begin{array}{c}\text { HMF } \\
\text { Conversion } \\
{[\%]}\end{array}$ & $\begin{array}{l}\text { Selectivity to } \\
\text { FDC [\%] }\end{array}$ & $\begin{array}{c}\text { HMF } \\
\text { Conversion } \\
{[\%]}\end{array}$ & $\begin{array}{l}\text { Selectivity } \\
\text { to FDC [\%] }\end{array}$ & $\begin{array}{c}\text { HMF } \\
\text { Conversion } \\
{[\%]}\end{array}$ & $\begin{array}{c}\text { Selectivity } \\
\text { to FDC } \\
{[\%]}\end{array}$ & & \\
\hline TE & 0.130 & 0.058 & 47 & 38 & 47 & 40 & 74 & 31 & 40 & 45 \\
\hline TEO & 0.047 & 0.036 & 21 & 71 & 21 & 88 & 37 & 83 & 71 & 88 \\
\hline TEO200 & 0.037 & 0.029 & 20 & 75 & 30 & 77 & 51 & 75 & 75 & 73 \\
\hline TEO300 & 0.040 & 0.016 & 20 & 48 & 16 & 52 & 33 & 46 & 47 & 50 \\
\hline TEO400 & 0.069 & 0.021 & 28 & 43 & 34 & 42 & 58 & 35 & 46 & 44 \\
\hline
\end{tabular}




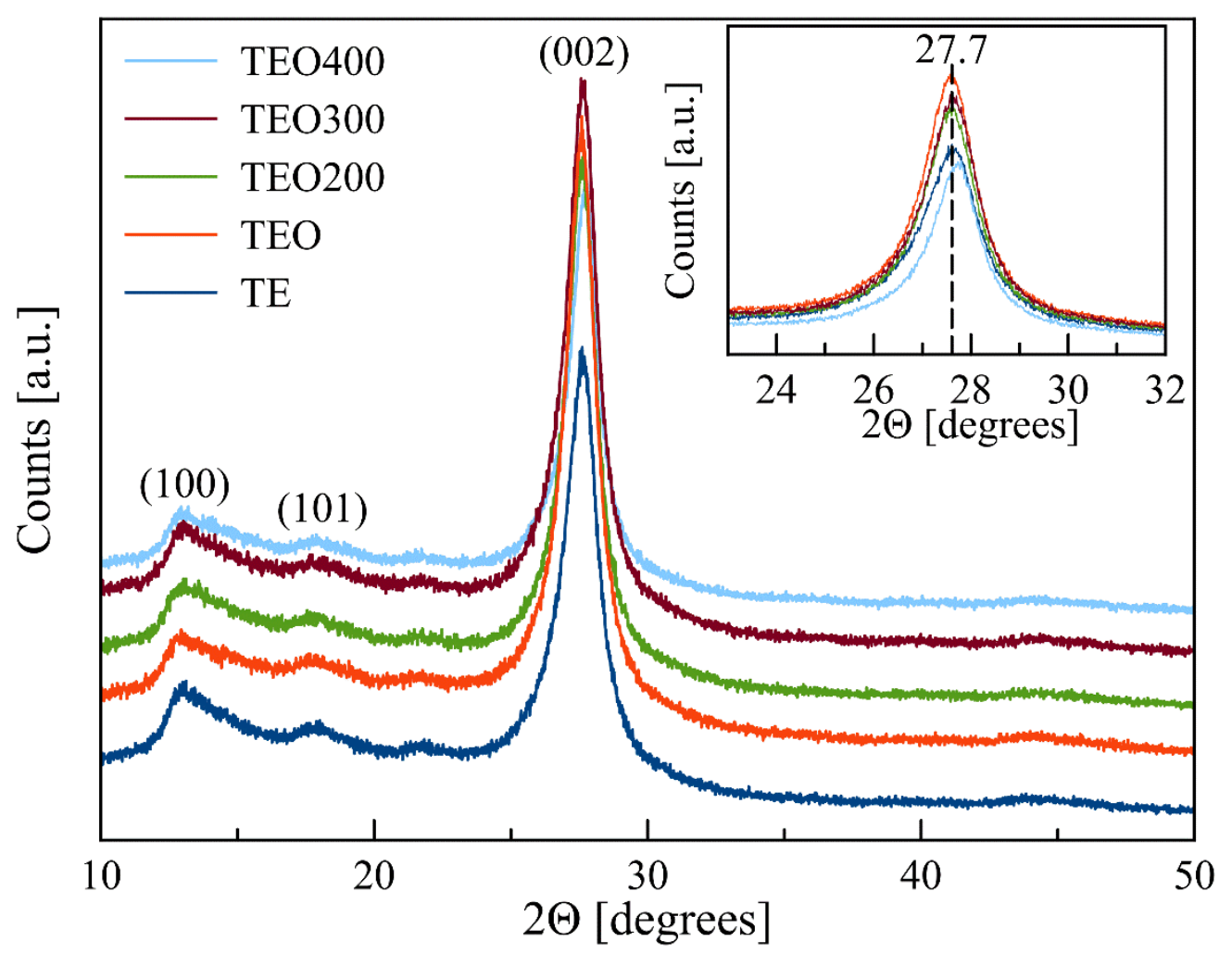

Fig. 1

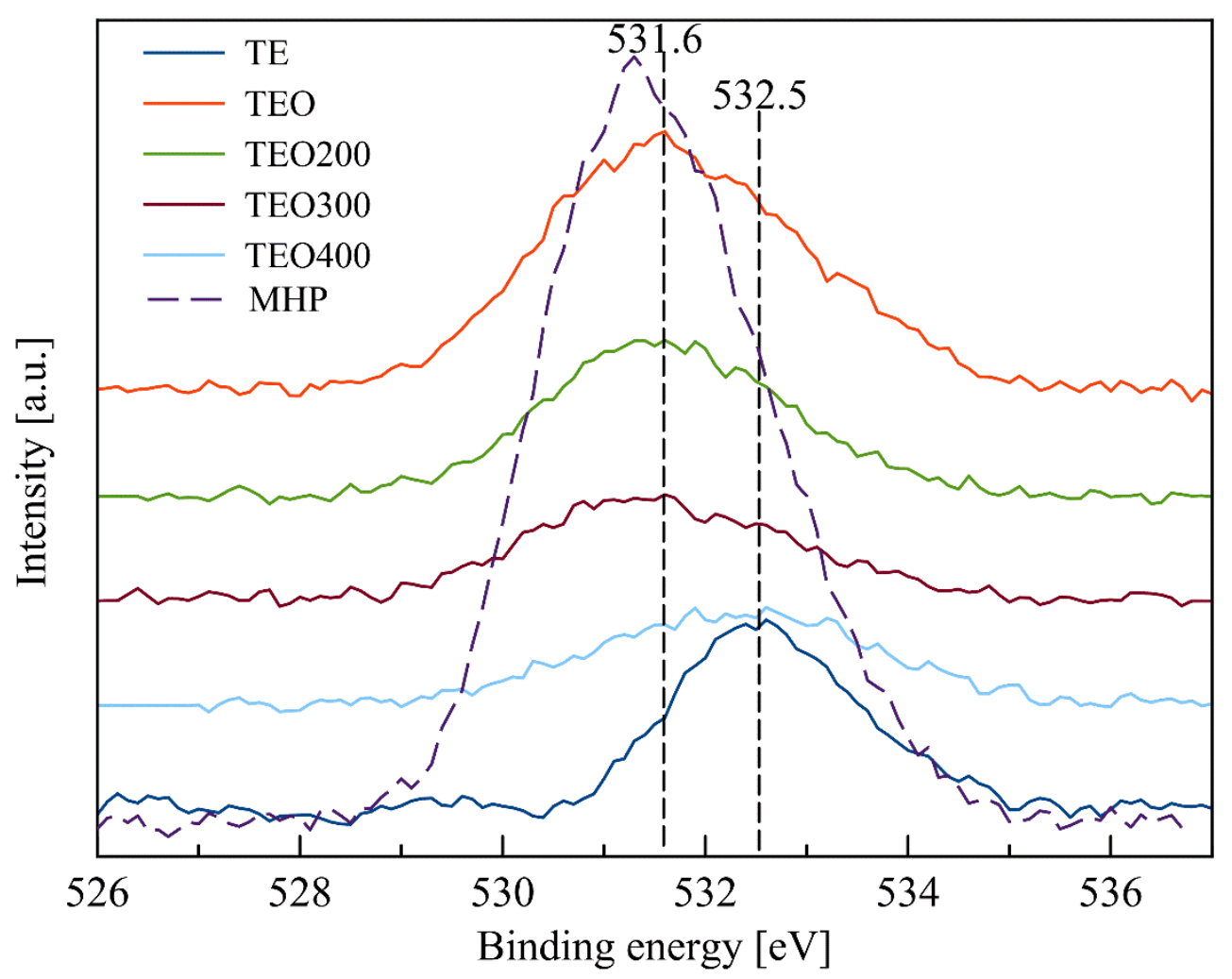

Fig. 2 


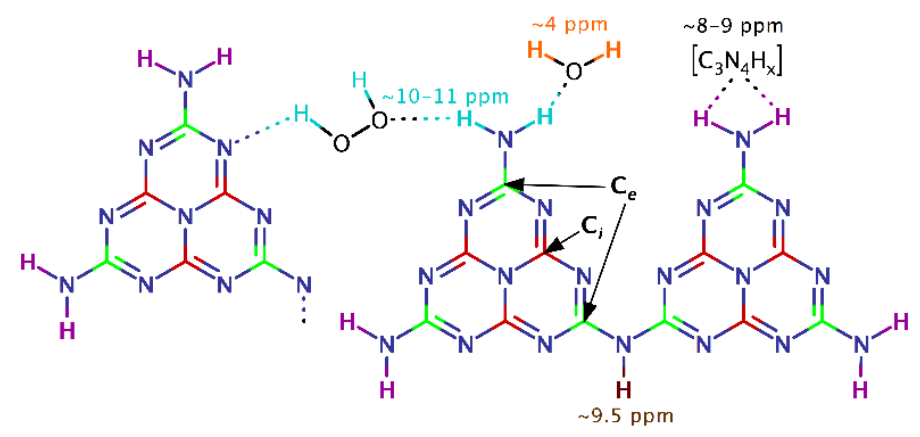

Fig. 3
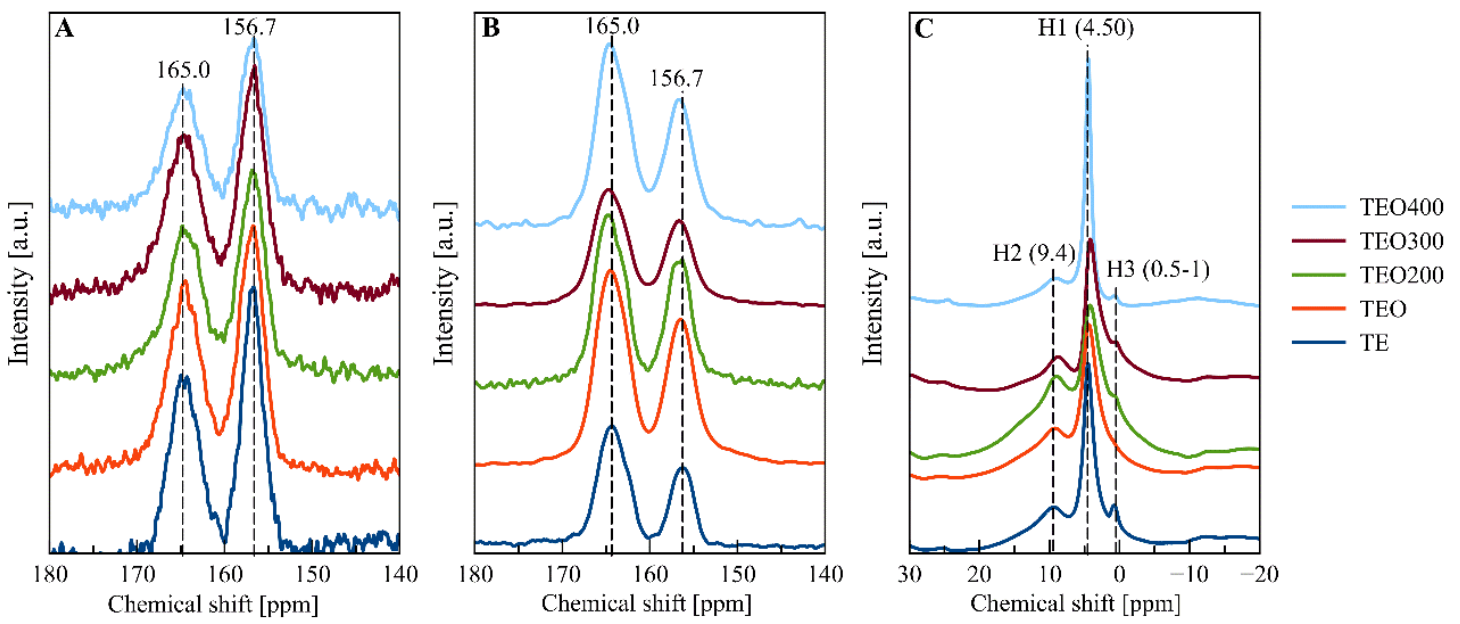

Fig. 4 

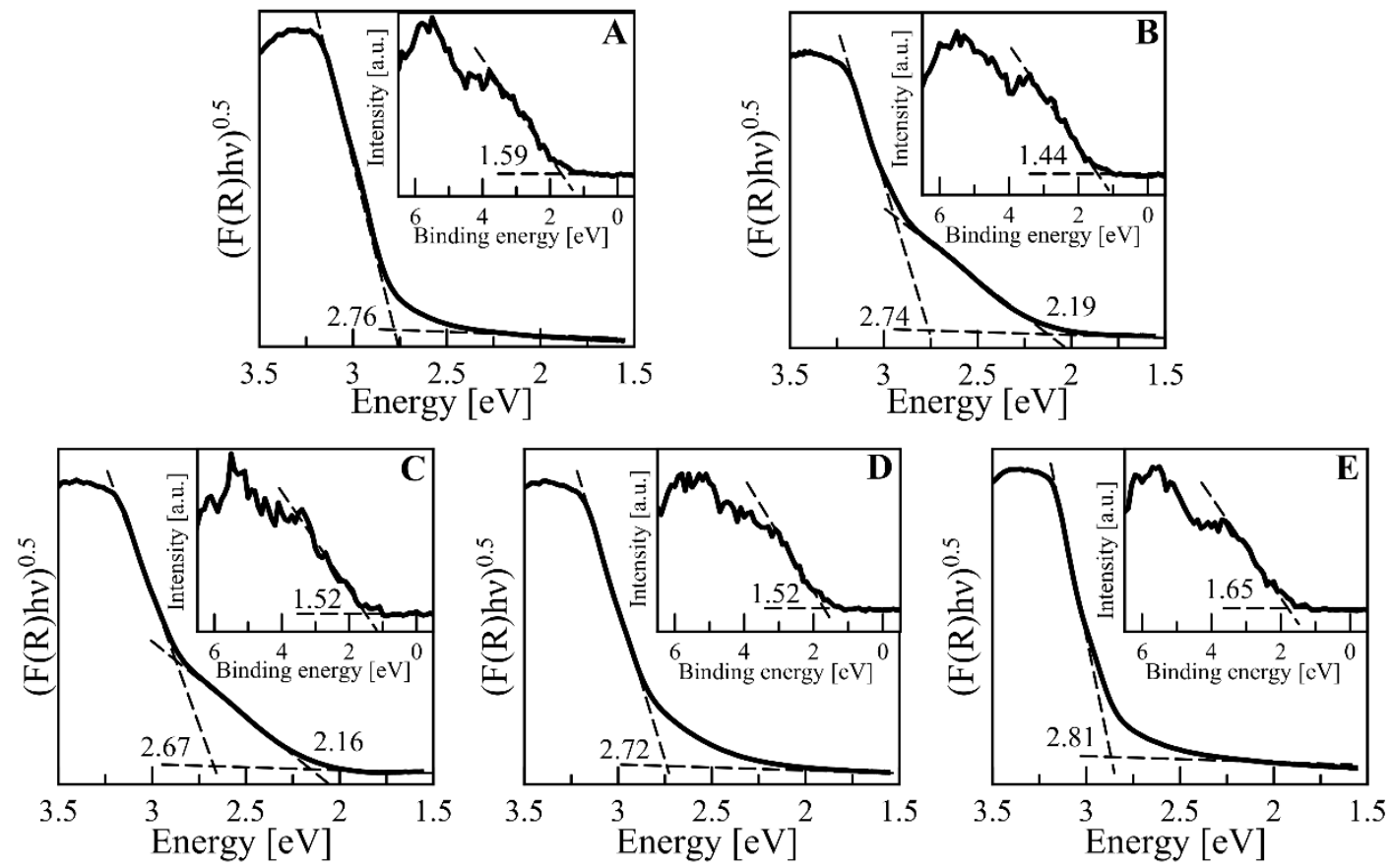

Fig. 5
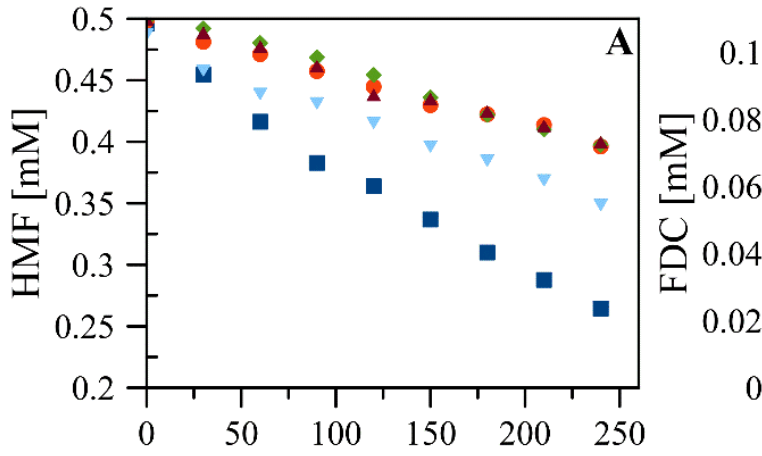

Time [min]
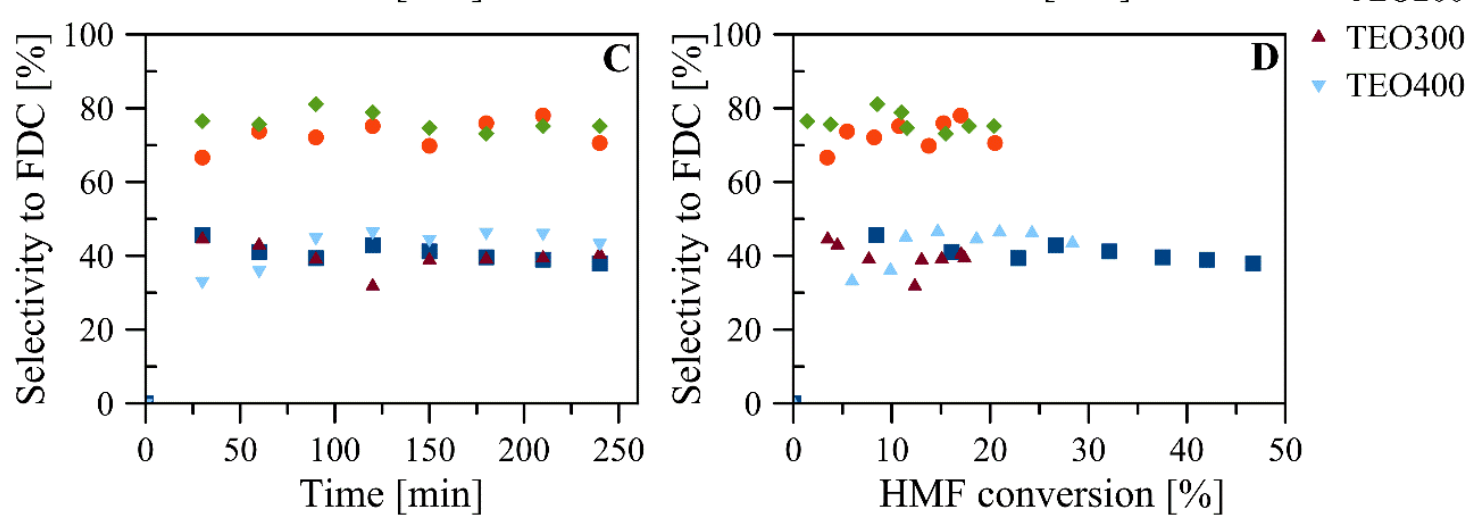

Fig. 6 

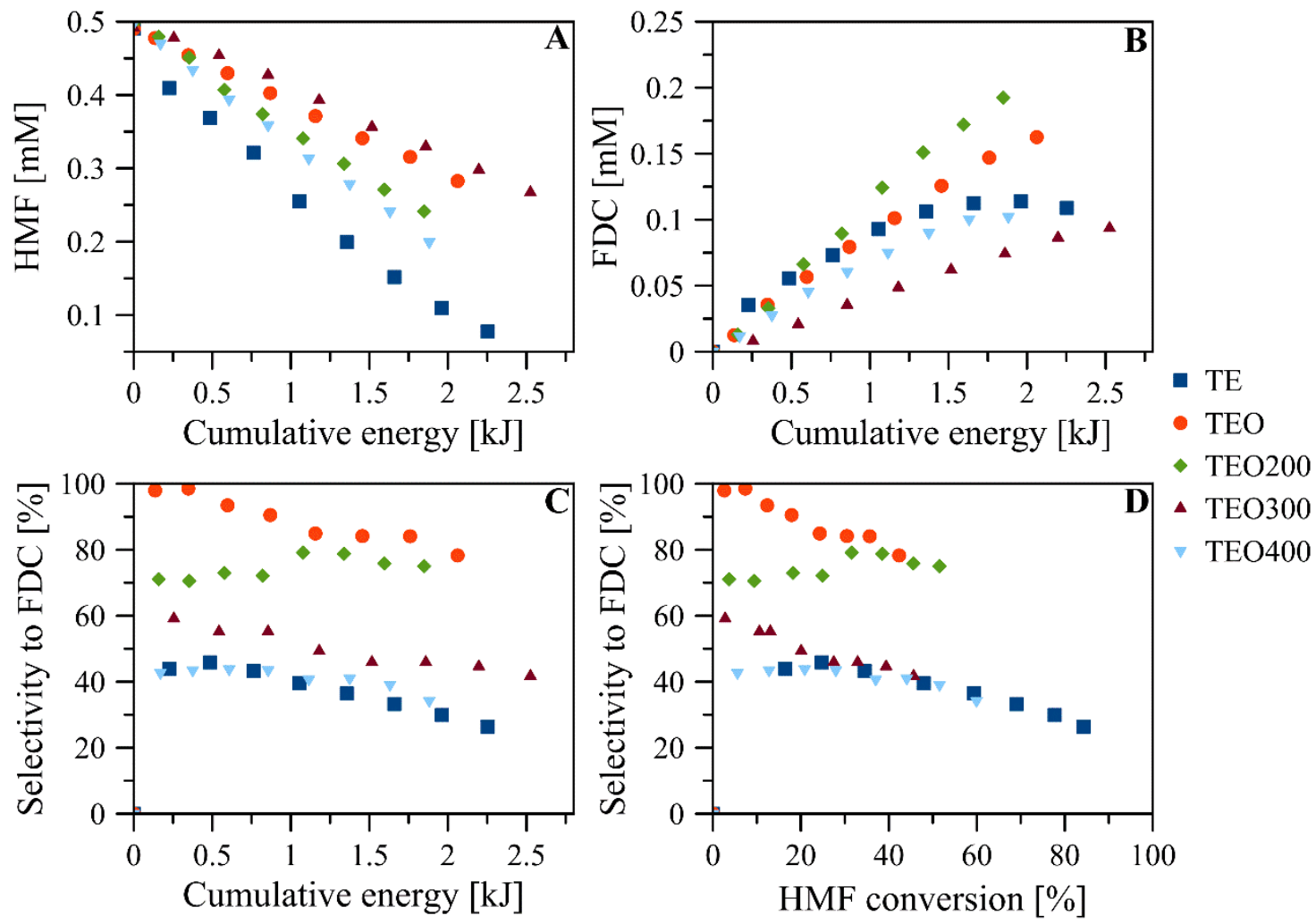

Fig. 7
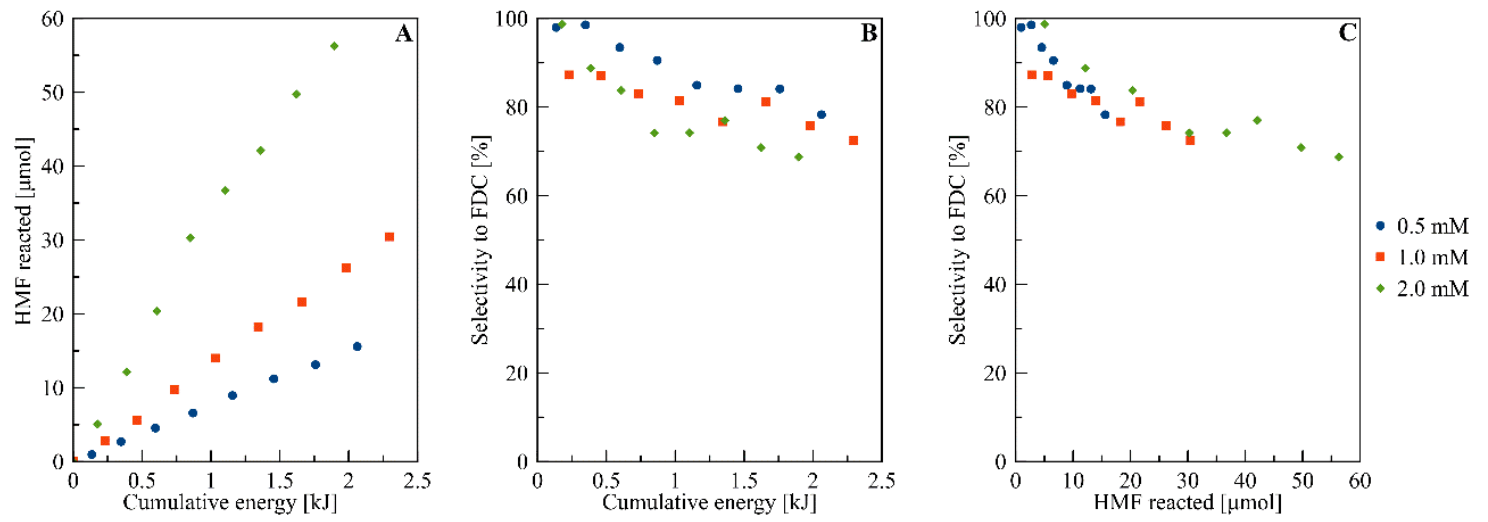

Fig. 8 


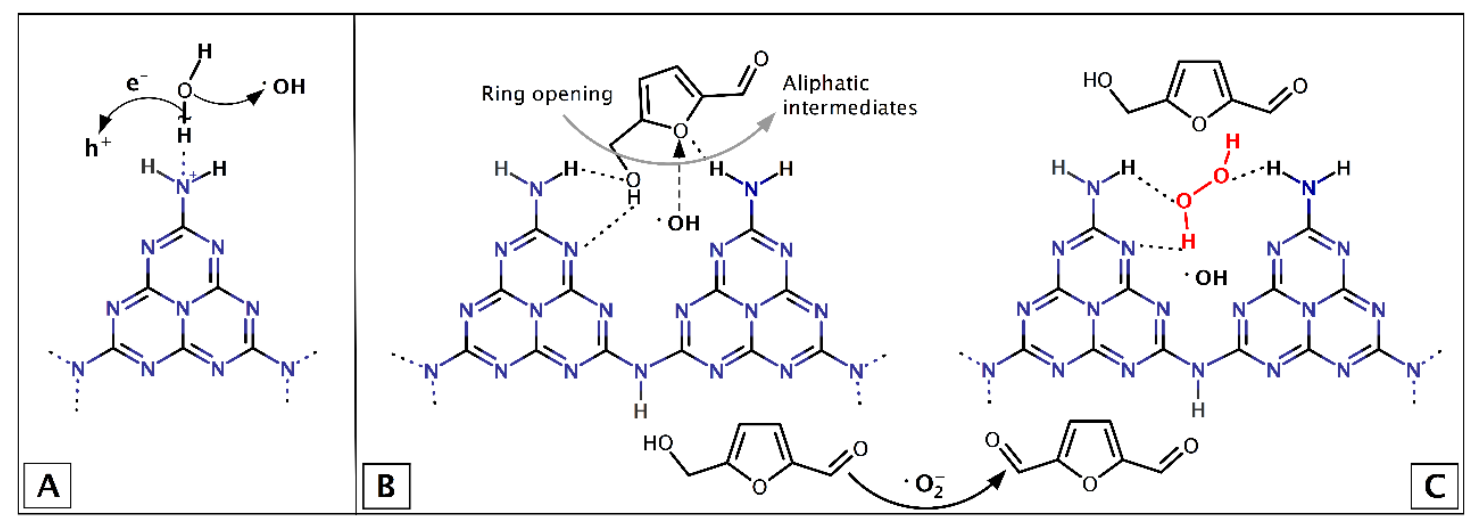

Fig. 9 